\title{
Food Science and Technology Students Self-Evaluate Soft and Technical Skills
}

\author{
Katherine M. Flynn ${ }^{*}$, Peter Ho ${ }^{\mathrm{b}}$, Margarida C. Vieira ${ }^{\mathrm{c}}$, Paola Pittia ${ }^{\mathrm{d}}$, And \\ Marco Dalla Rosa ${ }^{\mathrm{e}}$ \\ a The European Association for Food Safety, SAFE consortium, Rue Vanderborght, 20, 1081, Brussels, Belgium \\ ${ }^{\mathrm{b}}$ University of Leeds, School of Food Science and Nutrition, Leeds LS2 9JT, United Kingdom \\ ${ }^{\mathrm{c}}$ Universidade do Algarve, Instituto Superior de Engenharia, Campus da Penha, 8005-139 Faro, Portugal \\ ${ }^{\mathrm{d}}$ University of Teramo, Faculty of Bioscience and Technology for Food Agriculture and Environment, Via R. \\ Balzarini 1, 64100, Teramo, Italy \\ e University of Bologna, Interdepartmental Centre for Agri-Food Industrial Research, Alma Mater Studiorum, \\ Piazza Goidanich 60, Cesena (FC) \\ ${ }^{*}$ Corresponding author \\ katherine.flynn@safeconsortium.org
}

Received: 15 November 2016; Published online: 18 October 2017

Invited paper from the 4th International ISEKI Food Conference - ISEKI_Food 2016 - Bridging Training and Research for Industry and the Wider Community - Responsible Research and Innovation in the Food Value

\begin{abstract}
Food Scientists and Technologists (FS\&T) need diverse skills in the globalized food and drink sector: Food-specific or scientific / technical skills and generic or intuitive soft skills. This study determined how satisfied FS\&T students were with overall improvement, and in key technical and soft skills, based on their university work; and if satisfaction was linked to geography, degree in progress, anticipated degree, anticipated work place or anticipated job responsibility. An on-line survey was completed by 267 students in over 20 countries using a 5-point Likert scale to evaluate satisfaction. Responses were analyzed by the Friedman or Kruskal Wallis tests for more than two groups, otherwise by the Wilcoxon Signed Rank or Mann-Whitney tests. There were no differences in Overall Satisfaction with technical and soft skills training. Among soft skills, training in Working with Others and Being Responsible were more often rated "Excellent" and students were more satisfied with their training than with Solving Problems, Communication and Positive Attitude. Students anticipating a job with high responsibility were more satisfied with overall soft skill training and with 3 of the 5 specific soft skills. Among technical skills, students were more satisfied with improvement in basic sciences (Microbiology, Chemistry, Processing, Safety), and those in Northern Europe were more satisfied with overall technical training. These data show variations in perception and/or efficacy of technical and soft skill training in Food Science programmes and underline the need for separate attention to the incorporation of soft skill training into the design of FS\&T courses.
\end{abstract}

Keywords: Education; Soft skills; Food science; Satisfaction

\section{Introduction}

Food Scientists and Technologists (FS\&T) need many diverse skills to meet the needs of a globalized food and drink sector: Food-specific or scientific / technical skills and the more recently recognized generic or intuitive soft skills, which are broadly applicable across job titles and include interpersonal, communication and social skills. When FS\&T employers in Europe 
brainstormed ideal employee skills, $76 \%$ of these were soft skills (Flynn, Wahnstrom, Popa, RuizBejarano, \& Quintas, 2013). Despite this desire, employers tended to believe their FS\&T employees do not have sufficient soft skills, while the employees stated that they do: e.g., only $42 \%$ of FS\&T employers found their employees sufficient in Group Leadership while $92 \%$ of employees rated themselves as sufficient (Mayor et al., 2015). The importance of soft skills to food and drink employers and the disconnect on their presence in current employees merits further investigation and attention to soft skill acquisition for future FS\&Ts.

One of the goals of the ISEKI_Food 4 project (https://www.iseki-food4.eu) was the "development of learning and teaching approaches and activities able to improve and exploit the new skills for students in food studies in EU". This study was one of several addressing the broad ISEKI_Food 4 theme and the specific aim here was to determine how satisfied FS\&T students were with their improvement in key technical and soft skills. Furthermore, students were classified by demographic groups (geography, degree in progress, expected degree, expected place of employment, expected level of job responsibility) to see if satisfaction varied based on these variables. Satisfaction is a readily accepted concept that applies to all populations. Critics of restaurants, hotels, and movies often summarize their experience by stating their satisfaction. It is precisely this "personal" aspect of satisfaction that carries the most weight when evaluating student perception of their education. Measures of graduation and employment may be more common, but they lack the emotional impact of satisfaction.

The food and drink sector of the future will require employees with competencies in both technical and soft skills, and levels of student satisfaction can be instrumental in understanding the strengths and weaknesses of current food science curricula in meeting these requirements. Student self-assessment has been used for decades and was shown to accurately reflect learning (Brown \& Harris, 2013), and a meta-analysis showed the most accurate self-assessments among students in more advanced courses in the sciences (Falchikov \& Boud, 1989). The knowledge gained from student self-assessment can be used by food science educators to improve curricula and produce the food scientists and technologists needed for this rapidly changing sector.

\section{Materials and Methods}

\subsection{Questionnaire}

An online survey entitled "Training Tomorrow's Food Scientist \& Technologist" was available from May to November 2012 via the ISEKI_Food 4 website and advertised by email and other dissemination tools both within and outside of the ISEKI_Food 4 European project. Instructions guaranteed confidentiality and specified that the questionnaire was for current students of food science and food technology and that its ultimate aim was to generate innovative approaches in the training of FS\&Ts. The survey was ethically approved by the institutions involved and it contained information and consent elements.

Survey respondents were required to examine two lists of skills: seven technical skills divided into two categories and five soft skills divided into two categories. These skills were those previously identified as most desirable by FS\&T employers (Flynn, Ruiz-Bejarano, Wahnstrom, Echim, \& Quintas, 2013), complemented by several technical skills added by FS\&T faculty members (Table 1). Respondents were asked to give a grade to each skill indicating how satisfied s/he was with improvement based on work in university courses. A 5-point Likert scale, where A = Excellent, $\mathrm{B}=$ Good, $\mathrm{C}=$ Fair, $\mathrm{D}=$ Minimal and $5=$ Failing, was used. Respondents then gave an overall grade for level of satisfaction for both technical and soft skill improvement and listed the three technical and three soft skills believed to be most important for future jobs.

The following demographic information was collected: Country of study (open question), Degree in progress (Ph.D., Master, Bachelor, Technical), Anticipated highest degree (Ph.D., Master, Bachelor, Technical), Anticipated employer (Large Enterprise, Small or Medium Enterprise, Academic/Research, Government, Consultancy, Other) and Desired job responsibility (High=Responsible for several 
teams, Medium=Responsible for several people, Low $=$ Responsible for self).

\subsection{Data treatment and statistical analysis}

Percent of students choosing 'Excellent' for Overall Technical Skill Improvement was compared with percent choosing 'Excellent' for each of the 7 technical skills using the 'One sample t-test between percents' in StatPac ${ }^{\complement}$ statistical software. The same procedure was applied to compare individual soft skills to overall. The Bonferroni correction for multiple tests was applied, requiring $\mathrm{p} \leq 0.007$ for technical skills ( 7 comparisons) and $\mathrm{p} \leq 0.01$ for soft skills (5 comparisons).

Rank sums from the Likert scale responses were calculated using the Real Statistics $@$ add-on in Excel ${ }^{\circledR}$ for each of the 7 technical and 5 soft skills and these data were analysed by the same program using the non-parametric, repeated measures Friedman test for differences in satisfaction among the 7 technical and the 5 soft skills. If significant, this was followed by a post-hoc, the conservative 2-tailed Wilcoxon Signed Rank test for paired samples. The Bonferroni correction for multiple tests was applied, requiring $\mathrm{p} \leq 0.005$ for comparing each soft skill to each other (10 comparisons) and $\mathrm{p} \leq 0.002$ for comparing technical skills (21 comparisons) to determine if any differences existed between specific skills. The overall difference in satisfaction between technical and soft skills was compared using the 2tailed Wilcoxon Signed Rank test for paired samples.

For determining differences among demographic groups, the non-parametric Kruskal-Wallis test was used when students were divided into more than two groups (four geographical regions, four anticipated employment sectors, three anticipated degrees), followed by the 2-tailed MannWhitney post-hoc using the Bonferroni correction for multiple tests if the Kruskal-Wallis showed significance. Analysis of differences between two groups (current degree, desired level of job responsibility) used the 2-tailed MannWhitney test alone.

The uncorrected level of significance for each test was $95 \%$ confidence or $\mathrm{p}=0.05$.

\section{Results and Discussion}

\subsection{Questionnaires}

From May through November 2012, 267 questionnaires were collected from students (Table 2). All responding students answered all questions and there were no missing data. Responses came from over 21 countries and these were organized into 4 geographical regions. Northern and Southern Europe were well represented, with $71 \%$ of the responses coming from these two regions, likely due to the higher level of participation of higher education institutes in these countries in the ISEKI_Food 4 project. Nonetheless, the geographical spread of respondents gives a good sample of food science students, with the exception of a lack of representation from Africa. Respondents were equally divided between undergrads, that is those working towards a technical or Bachelor degree, and postgrads, that is those working towards a Master or Ph.D. A large majority of the students, $85 \%$, expected to eventually earn a postgraduate degree. This may indicate a trend towards growing professionalism in food science and technology. A recent study showed most employees with a university degree in food science had a Bachelor (Flynn, RuizBejarano, et al., 2013) while a later study, in which $75 \%$ of respondents were under 40 years old, showed equal numbers with a Bachelor and with a Master degree (Mayor et al., 2015), and here, most current students expect either a Master or a Ph.D. degree. Of course, what a person expects and what actually occurs may not be the same. Currently, the Bachelor and Master degrees are leading not only to different knowledge and skills but also to different specialisations within the broad area of Food Science and Technology disciplines. Only future surveys can confirm if FS\&Ts are truly trending towards higher levels of education.

The most popular response to the question planned place of employment was "enterprise", $57 \%$ of responses, of which almost half planned to work for small and medium sized enterprise (SME) and half for large enterprise. For this

\begin{tabular}{l|l|l|l} 
IJFS | October 2017 & Volume 6 & pages 129-138
\end{tabular} 
Table 1: List of technical and soft skills as presented to respondents

\begin{tabular}{llll}
\hline TECHNICAL SKILLS & & SOFT SKILLS & \\
\hline Research \& Development: & $\begin{array}{l}\text { Product Development } \\
\text { Food Microbiology } \\
\text { Food Chemistry } \\
\text { Food Processing }\end{array}$ & Fundamental: & Demonstrating Positive Attitudes \& Behaviour \\
& $\begin{array}{l}\text { Research, inc. Design \& Execution of Experiments } \\
\text { Food Safety Management, Food Hygiene \& Food Safety Control } \\
\text { Quality Management, Quality Assurance \& Quality Control }\end{array}$ & Personal Management: & $\begin{array}{l}\text { Communication } \\
\text { Thinking \& Solving Problems } \\
\text { Wood Quality \& Food Safeth Others }\end{array}$ \\
\hline
\end{tabular}

question, more than one response was accepted; the 267 respondents gave a total of 458 responses or an average of 1.7 responses per student, indicating that most students had a clear idea of where they plan to work. In fact, $70 \%$ of respondents gave only one answer for planned place of employment. Important for the European food and drink industry is that half of the food science students who would like to work for enterprise would like to work for an SME. SMEs are $99 \%$ of all European food and drink companies (FDE, 2015) and generate almost $50 \%$ of the food and drink industry turnover and value added and provide two thirds of the employment of the sector. Adding well educated FS\&Ts to these smaller food companies will surely contribute to maintaining Europe's position as a leader in the food sector, particularly for region-specific and traditional foods. Thus, encouragement of already interested food science students should be pursued at the university level and incorporation of work with and about food sector SMEs should be a continued segment of the food science university curriculum.

Respondents were almost equally divided on the amount of desired job responsibility once established in their career, with $59 \%$ desiring positions with low or mid responsibility, i.e., responsible for themselves or for several people, respectively, and $41 \%$ desiring high responsibility positions, i.e., responsible for several teams. The desire for high responsibility may be linked to the desire for a high level of education, although progressing towards executive positions has more so been linked to a "proactive" personality, including taking personal responsibility and looking for self-improvement (Seibert, Kraimer, \& Crant, 2001), and not necessarily to education. Thus, it appears here that the $41 \%$ of students desiring a high level of job responsibility are not necessarily a subset of the $85 \%$ desiring a high level of education; we should be careful to avoid the common perception, in the food and drink sector and elsewhere, that high job responsibility and high levels of education are linked.

\subsection{Satisfaction with skills}

Rank sums for Overall Satisfaction with improvement in technical skills and Overall Satisfaction with improvement in soft skills were not significantly different, $\mathrm{p}=0.78$. The percentage of students rating their Overall Satisfaction as "Excellent" for technical and soft skills training was also not significantly different, $\mathrm{p}=0.21$, with "Excellent" satisfaction reported by $19 \%$ and $24 \%$ of students for technical and soft skills, respectively (Figure 1)., and "Excellent" or "Good" satisfaction by $73 \%$ and $72 \%$, respectively (data not shown). In health care surveys, levels of satisfaction of $87 \%$ and above are not uncommon (Di Palo, 1997), and these authors suggested a tendency for ratings of general satisfaction to cluster at the high end of the scale. For the specified skills within the "Technical" and "Soft" categories there was not the same equality of satisfaction as seen for Overall. The percent stating "Excellent" improvement in the specific soft skills Working with Others, $44 \%$ at $\mathrm{p}=0.0001$, and Being Responsible, $39 \%$ at $\mathrm{p}=0.0019$, was higher than the percentage stating "Excellent" satisfaction for Overall, 24\%. Conversely, there were no differences between the percent of students stating "Excellent" satisfaction with improvement in specific technical skills versus overall technical improvement. This result may reflect unfamiliarity with the term "soft skills"; students were less likely to rate their overall im- 
Table 2: Questionnaire responses categorised by demographics

\begin{tabular}{|c|c|c|c|c|}
\hline \multirow{10}{*}{ Geographical Region: } & Central & North & South & Other \\
\hline & France & Ireland & Cyprus & Cambodia \\
\hline & Germany & Netherlands & Greece & Indonesia \\
\hline & Hungary & UK & Italy & Israel \\
\hline & Poland & & Portugal & Nepal \\
\hline & Slovenia & & Spain & Philippines \\
\hline & & & & Russia \\
\hline & & & & Thailand \\
\hline & & & & Unspecified \\
\hline & $36(13 \%)$ & $108(40 \%)$ & $82(31 \%)$ & $41(15 \%)$ \\
\hline Degree in Progress: & \multicolumn{2}{|c|}{$\begin{array}{c}\text { Technical or Bachelor } \\
133(50 \%)\end{array}$} & \multicolumn{2}{|c|}{$\begin{array}{c}\text { Master or Ph.D. } \\
134(50 \%)\end{array}$} \\
\hline Highest Degree Expected: & $\begin{array}{c}\text { Technical or Bachelor } \\
39(15 \%)\end{array}$ & \multicolumn{2}{|r|}{$\begin{array}{c}\text { Master } \\
129(48 \%)\end{array}$} & $\begin{array}{l}\text { Ph.D. } \\
99(37 \%)\end{array}$ \\
\hline Anticipated Employer: & $\begin{array}{c}\text { Academic/ Research } \\
90(34 \%)\end{array}$ & $\begin{array}{c}\text { SME } \\
121(45 \%)\end{array}$ & $\begin{array}{c}\text { Large Enterprise } \\
\qquad 141(53 \%)\end{array}$ & $\begin{array}{c}\text { Other } \\
106(40 \%)\end{array}$ \\
\hline Job Responsibility & $\begin{array}{l}\text { Low/Mid } \\
157(59 \%)\end{array}$ & & $\begin{array}{r}\text { High } \\
110(41 \%\end{array}$ & \\
\hline
\end{tabular}

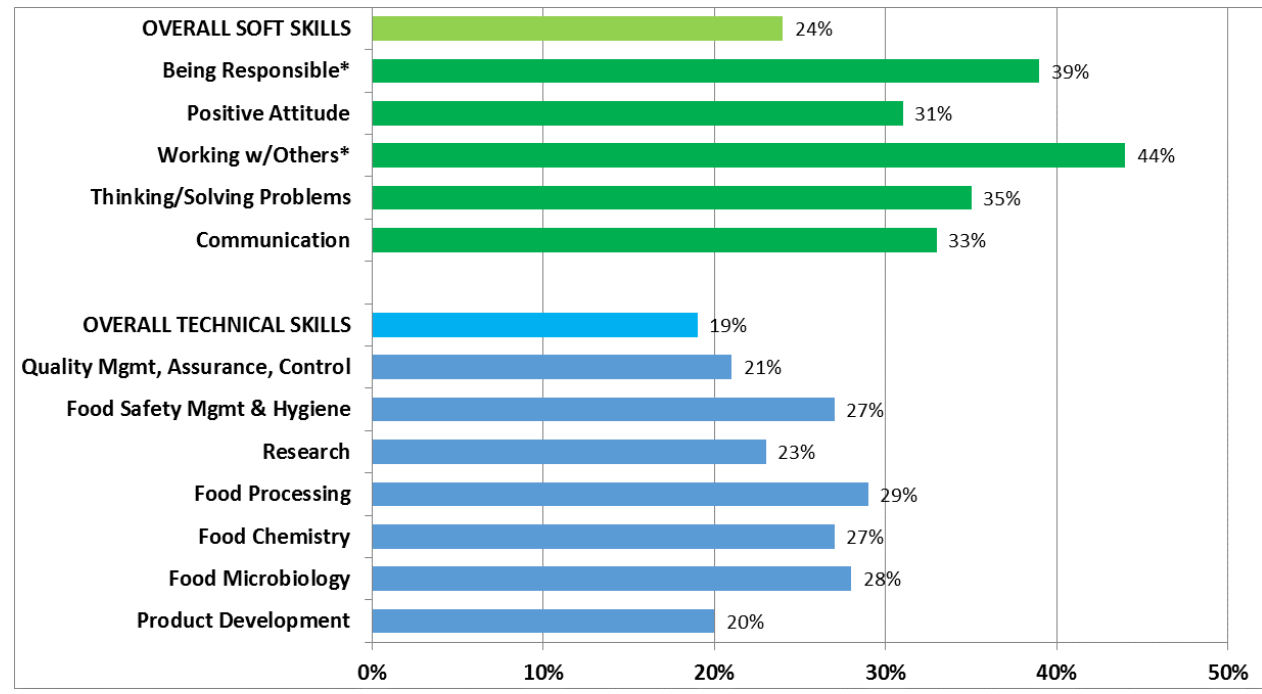

Figure 1: Percentage of students who chose "Excellent" for satisfaction with their "overall improvement" in Soft Skills and in the 5 specified soft skills and for their "overall improvement" in Technical Skills and in the 7 specified technical skills. ${ }^{*}$ indicates percentage is significantly different from Overall for that skill group, $\mathrm{p}<0.002$. 
provement as excellent or very good being not completely sure what they had improved in, yet when asked about specific soft skills, such as $B e$ ing Responsible, they had a clearer understanding. Conversely, students were satisfied with the overall idea of their technical training, perhaps having the pre-conceived idea that a food science education provides strong technical training, and equally satisfied when focusing on specific technical skills that they were already familiar with.

\subsection{Satisfaction with technical skills}

There was a significant difference in satisfaction with improvement among the 7 specific technical skills $\left(\mathrm{p}<3.6 \times 10^{-} 7\right)$. Post hoc analysis (Figure $2 \mathrm{~A}$ ) showed that the skills were divided into two groups, with students more satisfied with their training in Food Microbiology, Food Processing, Food Chemistry, and Food Safety \& Hygiene than with their training in Food Quality Management, Assurance \& Control $(p<0.001)$, Product Development $(p<0.0002)$ and Research $(p<0.00002)$. If the respondents were primarily undergraduates, it would be understandable that they were more satisfied with their improvement in more basic science courses i.e., Microbiology and Chemistry than in more advanced and even post-graduate courses i.e., Food Quality, Product Development and Research as in general these are disciplines included in $2^{\text {nd }}$ level/Master degree and Ph.D. programmes. However, one half of the respondents were working on a Master or Ph.D. and thus it is surprising and somewhat disconcerting that, on average, $40 \%$ of food science students found their improvement in these three food-specific courses to be "Fair", "Minimal" or "Failing". The dissatisfaction that food science students have with their training in Research may later contribute, once they are in the working world and particularly in industry, to the low R\&D investment found in EU food and drink enterprises, which are rated as a Medium-Low intensity sector (together with Travel \& Leisure, Media, etc.), accounting for only $6 \%$ of $€ 171$ billion invested in European R\&D (EC, 2015). University training in Research is part of many scientific disciplines, including the Food Science programmes at the authors' home universities. It generally encompasses course work in experimental design, research methods and statistical analysis; often students work closely with a faculty mentor on a specific research project. If research is seen as a pre-requisite for innovation, and innovation as a requirement for continued growth and improvement, then the results here suggest that increased attention to training future $\mathrm{Eu}-$ ropean food scientists in research is needed, and likely applied research oriented towards industry and with attention to knowledge and technology transfer will be the most beneficial. A hard look at the current presentation of research to FS\&T students can start with sharing opinions and best practices among FS\&T educators, followed by ambitious changes and careful monitoring of the results - this will likely require investment of time and money by universities. The increased student satisfaction, and later success in research will be a well-deserved outcome and one which might move the food sector up from its current position as a Medium-Low R\&D investment sector and later confer the benefits that robust R\&D brings to industry.

There was only one significant difference in student assessment of their improvement in technical skills based on demographics, and that was an interaction between Overall Satisfaction with technical skills and Geographic Region (Figure 2B), which showed students in the north of Europe three times more satisfied than those in the South $(\mathrm{p}<0.002)$. This is consistent with rankings which place the top universities in the northern countries of UK, Sweden, Switzerland and Germany (THE, 2016). High student satisfaction with technical training may be linked to higher funding for universities in Northern Europe and thus more advanced technical equipment. Importantly, satisfaction with improvement in soft skills was not linked to Geographic Region, thus apparently not linked to attending a higher ranked university or higher funding, and suggesting separate frameworks for the teaching and learning of technical and soft skills. This further suggests that effective soft skill teaching and learning are independent of funding and equipment but rely on other, perhaps less tangible, resources. An interesting and important question for further research is to identify the resources 


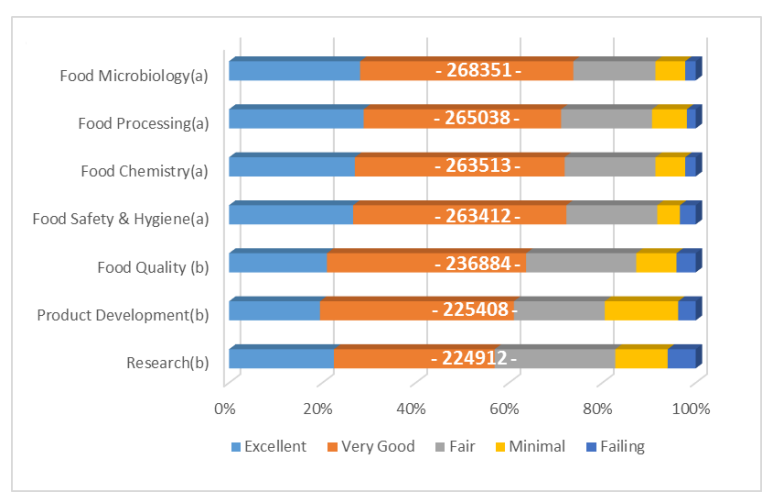

(a)

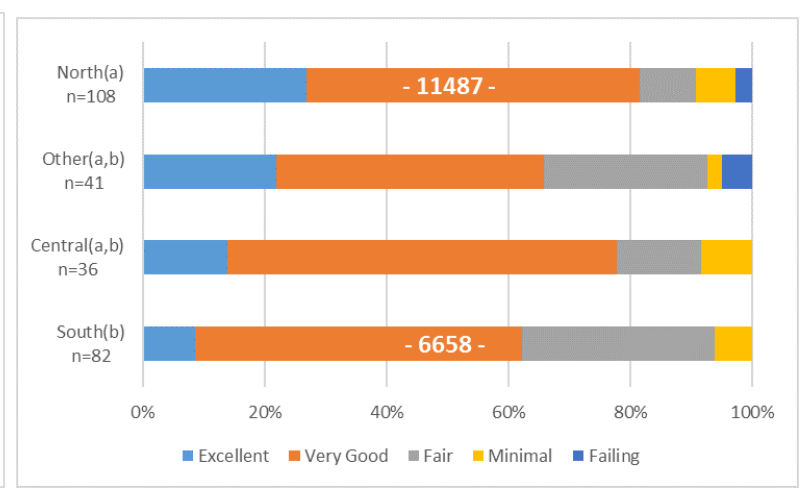

(b)

Figure 2: A) Among Technical Skills, food science students were more satisfied with their progress in Food Microbiology, Food Processing, Food Chemistry and Food Safety than with their progress in Food Quality, Product Development and Research. $\mathrm{p}<0.001$. B) Students in the North of Europe were more satisfied with their overall training in technical skills than were students in the South of Europe. $\mathrm{p}<0.002$. Numbers indicate rank sum for each skill. Ranks for skills with the same letter are not significantly different.

necessary for success in soft skill education.

\subsection{Satisfaction with soft skills}

There was a significant difference in satisfaction with improvement among the 5 specific soft skills $(\mathrm{p}<0.02)$. Post hoc analysis (Figure $3 \mathrm{~A})$ showed students were most satisfied with their training in Working with Others and Being Responsible, significantly more than with their training in Communication $(\mathrm{p}<0.0007)$ and Demonstrating Positive Attitudes $\&$ Behaviours $(\mathrm{p}<0.0003)$. Having "a team approach", or Working with Others was identified as an important soft skill by a national study to determine training recommendations for the food sector in Ireland (EGFSN, 2009) and "having a sense of responsibility and commitment" or Being Responsible was among the crucial soft skills listed by a U.S. focus group study with food industry executives (Napoleon, Freedman, Seetharaman, \& Sharma, 2006). Thus, overall, students are highly satisfied with their improvement, and therefore apparently receiving good instruction in soft skills valued by the food sector.

The respondents here, however, were significantly less satisfied with their training in Communication skills, whose importance for food science and technology professionals cannot be overstated. A survey of skills most desired by European employers in the food and drink sector showed communication to be the single most sought after skill (Flynn, Ruiz-Bejarano, et al., 2013). In the chemical industry, high level representatives listed communication as the number 1 personal skill for engineers (CEFIC, 2009) and, in Australia, communication is being integrated into some university engineering courses (Armstrong \& Baillie, 2011). In the medical profession, communication skills influence patient ratings of technical competence: Physicians judged to be good communicators were also believed to be technically competent (Robin DiMatteo \& Hays, 1980). This link between technical skill and ability to communicate needs recognition from the food and drink sector; food industry and food regulators are often in the public eye and the ability to communicate well can mean the difference between public vilification or public respect. As judged by students, the training of FS\&Ts in communication skills needs focus and significantly more attention.

Demographics of the respondents showed a statistically significant interaction between Overall Satisfaction with soft skills and Desired Job Responsibility (Figure 3B). Students who de- 


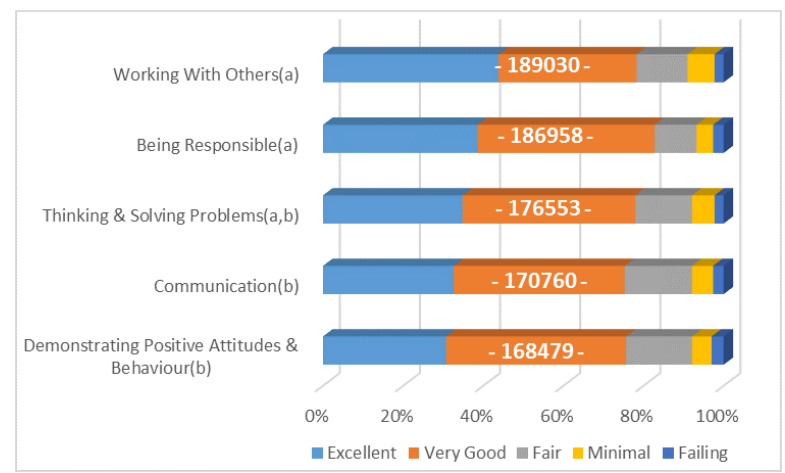

(a)

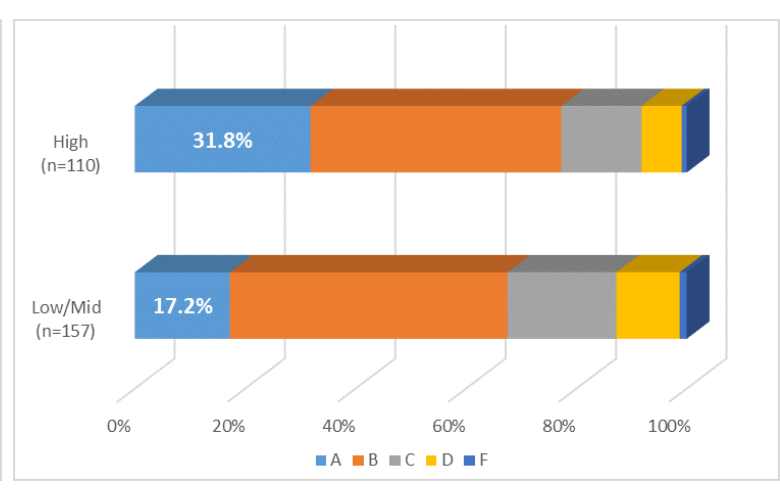

(b)

Figure 3: A) Among Soft Skills, food science students were more satisfied with their progress in Working with Others and Being Responsible than with their progress in Communication and Demonstrating Positive Attitudes $\&$ Behaviour. p<0.0003. B) Students anticipating a High Responsibility position were more satisfied with their overall training in Soft Skills than were students anticipating Low or Mid-level Responsibility. $\mathrm{p}<0.007$. Numbers indicate rank sum for each skill. Ranks for skills with the same letter are not significantly different.

sired a high responsibility position were significantly more satisfied overall $(\mathrm{p}<0.007)$, and for three specific soft skills, Demonstrating Positive Attitudes \& Behaviours, Being Responsible and Thinking 85 Solving Problems (data not shown) than those desiring mid or low responsibility work. There was no interaction between "Overall Satisfaction with soft skills" and level of anticipated education, suggesting again that students who anticipate a high degree are not the same as those who anticipate a high responsibility job. This further supports the work of Seibert et al. (2001), which showed executive positions linked to being "proactive", and suggested that innate personality may predispose a person to attain high responsibility work. It is possible that the personality that tends to achieve high responsibility positions is also the one that views improvement in a positive light; meaning they are more likely to be satisfied given the same results as others. Conversely, those with a "proactive" personality may actually get the most benefit from current methods of soft skill education in the food science curriculum. They are more satisfied because they did actually have better results. In either case, in the food sector, it is clear that high levels of education are not necessarily linked to high responsibility work and thus it is important to stress the soft skills associated with high responsibility at all educational levels.

\section{Conclusions}

The geography and current educational level of respondents gave a good, though small, sample of food science and technology students. Based on this, FS\&Ts appear to be trending towards higher levels of education, with more students aiming for a Ph.D. than in previous years, but divided on the amount of desired job responsibility and having a strong interest in working for small and medium sized enterprises.

Slightly more than $70 \%$ of surveyed students rated "Overall Satisfaction" with their improvement in the listed skills as excellent or good. This is a satisfactory result, but should not lead to complacency in food science education. Students were most satisfied with progress in Microbiology, Chemistry, Food Safety and Food Processing, highlighting the efficacy of food safety training in the FS\&T curriculum. Disconcerting for the researcher is the low student satisfaction with training in Research. Research and development have long been accepted as leading to growth in productivity and, more recently, to the innovations needed to underpin the food 
and agricultural systems of the future (EAFS, 2013; ETPFL, 2012), thus research must be a successful part of food science education. Students in the north of Europe were most satisfied with improvement in technical skills; while high soft skill satisfaction was found in those anticipating jobs with high responsibility. A closer look at this satisfied group could provide information on how to effectively teach soft skills. The placement of Communication in the group of lower satisfaction soft skills raises concern because communication was clearly identified as the single most important skill to FS\&T employers (Flynn, Wahnstrom, et al., 2013). Science and technology faculties must put more focus on effectively teaching communication skills. In conclusion, there is room for improvement in student satisfaction with their education in FS\&T and universities might do well to gather specific input from current and past students when (re)designing food science curricula. The growing importance of the food sector means that excellence in food science and technology education is a necessary component in facing the grand global challenges of the coming years.

\section{Acknowledgements}

The authors thank the 267 Food Science students who took time from their busy day to complete this on-line survey and also the partners in ISEKI_Food 4 who gave constructive criticism to a first draft of the survey and then distributed the final survey to their classes and their colleagues. This work was funded by the project 'ISEKI_Food 4, Toward the innovation of the food chain through the modernization of food studies' a grant through the Lifelong Learning Programme of the Commission of the European Communities, grant agreement number: 20113634. The funders had no role in the details of the study design; data collection analysis and interpretation; writing of the report; nor decision to publish. None of the authors of this manuscript have had any financial, personal, or other relationships with any people or organizations that could inappropriately influence this work.

\section{References}

Armstrong, R. \& Baillie, C. (2011). What! No Lectures? The facilitation of learning about the engineering challenges of the 21st century. Australian Association of Engineering Education (AAEE) Conference Abstracts, 18. Retrieved from http : / / www . aaee . com.au/conferences / 2011/docs / AAEE\% 202011\%20Conference\%20Abstracts.pdf

Brown, G. T. L. \& Harris, L. R. (2013). Sage handbook of research on classroom assessment. In J. H. McMillan (Ed.), (Chap. Student self-assessment, pp. 367393). Sage Thousand Oaks, CA. doi:10 . 4135/9781452218649.n21

CEFIC. (2009). European Chemical Industry Council. Skills for Innovation in the European Chemical Industry. Brussels BE. Retrieved from http://www. cefic.org / Documents / PolicyCentre / Skills - for Innovation - in - the - European - Chemical Industry.pdf

Di Palo, M. T. (1997). Rating satisfaction research: is it square poor, square fair, square good, square very good, or square excellent? Arthritis Care and Research, 10(6), 422-430. doi:10.1002/art.1790100610

EAFS. (2013). European Association for Food Safety, SAFE Consortium. Keeping food safety on the agenda. Brussels BE: SAFE Consortium. Retrieved from http://www. safeconsortium . org / index $\cdot$ php ? option = com_content $\% 5 \mathrm{C} \&$ view $=$ article $\% 5 \mathrm{C} \& \mathrm{id}=$ 1388:keeping-food-safety-on-the-agenda $\%$ 5 C\&catid $=111$ :publications $\% 5$ C\&Itemid $=$ 789

EC. (2015). European Commission, Joint Research Commission, Industrial Research and Innovation. EU R\&D Scorecard: The 2015 EU Industrial R\&D Investment Scoreboard. (Report EUR 27540 EN). Luxembourg: Publications Office of the European Union. doi:10.2791/15792

EGFSN. (2009). Expert Group on Future Skills Needs. Future skills requirements of the food and beverage sector. Dublin IE: EGFSN. Retrieved from http : / / www . skillsireland .ie / media/egfsn091120_skills_ food_beverage.pdf 
ETPFL. (2012). European Technology Platform Food for Life. (2012) Strategic research and innovation agenda (2013-2020 and Beyond). Brussels BE. Retrieved from http:// www . fooddrinkeurope. eu / uploads / pressreleases_documents / SRIA_ETP_Food_for_ Life_2012.pdf

Falchikov, N. \& Boud, D. (1989). Student self-assessment in higher education: a meta-analysis. Review of Educational Research, 59(4), 395-430. doi:10 . 3102/ 00346543059004395. eprint: http://dx.doi. org/10.3102/00346543059004395

FDE. (2015). Food Drink Europe. Data and Trends of the European Food \& Drink Industry. Brussels BE. Retrieved from http: / / www . fooddrinkeurope.eu/publication/ data - trends - of - the- european - food - and drink-industry-2016/

Flynn, K., Ruiz-Bejarano, B., Wahnstrom, E., Echim, C., \& Quintas, M. A. C. (2013). Profile of currently employed european food scientists and technologists: education, experience and skills. International Journal of Food Studies, 2(2), 37-149. doi:10.7455/ijfs/2.2.2013.a1

Flynn, K., Wahnstrom, E., Popa, M., RuizBejarano, B., \& Quintas, M. A. C. (2013). Ideal skills for european food scientists and technologists: identifying the most desired knowledge, skills and competencies. Innovative Food Science \& Emerging Technologies, 18, 246-255. doi:10.1016/j.ifset.2012. 09.004

Mayor, L., Flynn, K., Dermesonluoglu, E., Pittia, P., Baderstedt, E., Ruiz-Bejarano, B., ... Costa, R. (2015). Skill development in food professionals: a european study. European Food Research and Technology, 240(5), 871-884. doi:10.1007/s00217-014$2400-z$

Napoleon, L., Freedman, D., Seetharaman, K., \& Sharma, P. (2006). An educational needs assessment of pennsylvania workforce: opportunities to redefine secondary career and technical education to meet food industry needs. Journal of Food Science Education, 5(2), 19-23. doi:10.1111/j.15414329.2006.tb00077.x
Robin DiMatteo, M. \& Hays, R. (1980). The significance of patients' perceptions of physician conduct. Journal of Community Health, 6(1), 18-34. doi:10 . 1007/ BF01324054

Seibert, S. E., Kraimer, M. L., \& Crant, J. M. (2001). What do proactive people do? a longitudinal model linking proactive personality and career success. Personnel Psychology, 54(4), 845-874. doi:10.1111/ j . 1744-6570.2001.tb00234.x

THE. (2016). Times Higher Education. World University Rankings. Retrieved from https: //www.timeshighereducation.com/worlduniversity-rankings/2016/world-ranking \# ! / page / 0 / length / 25 / sort_by / rank / sort_order/asc/cols/stats 